\title{
A Role for Voltage-Gated Potassium Channels in the Outgrowth of Retinal Axons in the Developing Visual System
}

\author{
Sarah McFarlane and Natashka S. Pollock \\ University of Calgary, Department of Cell Biology and Anatomy, Calgary, Alberta T2N 4N1, Canada
}

Neural activity is important for establishing proper connectivity in the developing visual system. Tetrodotoxin blockade of sodium $\left(\mathrm{Na}^{+}\right)$-dependent action potentials impairs the refining of synaptic connections made by developing retinal ganglion cells (RGCs), but does not affect their ability to get out to their target. Although this may suggest neural activity is not required for the directed extension of RGC axons, in many species developing RGCs express additional, $\mathrm{Na}^{+}$-independent ionic mechanisms. To test whether the ability of RGC axons to extend in a directed fashion is influenced by membrane excitability, we blocked the principal modulators of the neural activity of a neuron, voltagedependent potassium (Kv) channels. First, we showed that
RGCs and their growth cones express Kv channels when they are growing through the brain on the way to their main midbrain target, the optic tectum. Second, a Kv channel blocker, 4-aminopyridine (4-AP), was applied to the developing Xenopus optic projection. Blocking Kv channels inhibited RGC axon extension and caused aberrant routing of many RGC fibers. With the higher doses, $<25 \%$ of embryos had a normal optic projection. These data suggest that Kv channel activity regulates the guidance of growing axons in the vertebrate brain.

Key words: axon guidance; Xenopus; target recognition; growth cone; electrical activity; neurite outgrowth; voltagedependent potassium channels
The tip of a growing axon, the growth cone, samples cues in its environment. How it responds may depend on intrinsic properties of the growth cone, such as second messenger systems, that are dynamic in nature. For example, brain-derived neurotrophic factor (BDNF) is chemoattractive for Xenopus spinal cord neurons, but is repulsive if growth cone cAMP levels are decreased (Song et al., 1997). Likewise, small changes in intracellular calcium $\left(\left[\mathrm{Ca}^{2+}\right]_{\mathrm{i}}\right)$ in either direction can result in neurite retraction or extension depending on the cell type (Mills and Kater, 1990).

One mechanism for altering $\left[\mathrm{Ca}^{2+}\right]_{\mathrm{i}}$ is via depolarizationinduced opening of high and/or low voltage-activated $\mathrm{Ca}^{2+}$ channels (Gottmann and Lux, 1995). This manipulation inhibits neurite elongation in some neurons and enhances it in others (Kater and Mills, 1991). If depolarization occurs in a spatially restricted manner, the increase in $\left[\mathrm{Ca}^{2+}\right]_{\mathrm{i}}$ and change in filopodia behavior are similarly restricted (Davenport and Kater, 1992). These data raise the possibility that electrical activity, via regulation of $\left[\mathrm{Ca}^{2+}\right]_{\mathrm{i}}$, could modulate motility and guidance (Neely and Nicholls, 1995).

In the developing visual system, impulse activity is critical for retinal ganglion cell (RGC) synaptic rearrangements, because blockade of $\mathrm{Na}^{+}$-dependent action potentials (APs) with tetrodotoxin (TTX) disrupts the process (Shatz, 1990). TTX does not affect RGC axon extension or pathfinding, arguing that RGC axons need not be electrically active to grow out to their target

\footnotetext{
Received Aug. 4, 1999; revised Oct. 25, 1999; accepted Nov. 3, 1999.

This work was supported by an operating grant from the Medical Research Council of Canada and an establishment grant from the Alberta Heritage Foundation for Medical Research. We thank Dr. R. J. A. Wilson for his helpful comments on this manuscript and M. Timmons for technical assistance. We are gratef ul to Dr. A. Ribera for providing us with the Xenopus cDNA clones for in situ hybridization, to Drs. A. Bulloch and W. Wildering for the use of their patch-clamp set up, and to Dr. D. Kaplan for the pan-trk and trkB antibodies.

Correspondence should be addressed to Dr. S. McFarlane, University of Calgary, Department of Cell Biology and Anatomy, HMB Room 171, 3330 Hospital Drive NW, Calgary, Alberta T2N 4N1, Canada. E-mail: smcfarla@acs.ucalgary.ca. Copyright (c) 2000 Society for Neuroscience 0270-6474/00/201020-10\$15.00/0
}

(Harris, 1980; Stuermer et al., 1990). Many developing neurons, however, express ion channels and generate $\mathrm{Ca}^{2+}$ spikes before they are able to generate $\mathrm{Na}^{+}$-dependent APs (Gu and Spitzer, 1997; Robinson and Wang, 1998). Thus, directed RGC axon extension might depend on a TTX-insensitive form of excitability. If true, modulation of this activity should influence growth cone behavior. Kv currents are important regulators of cellular excitability, functioning to modulate the amplitude, duration, and frequency of APs and subthreshold depolarizations. Altering Kv channel function is useful in revealing the cellular processes that are regulated by excitability (Ribera and Spitzer, 1992). Recently, $\mathrm{Kv}$ channels were overexpressed in Caenorhabditis elegans sensory neurons to examine a role for activity in axon connectivity (Peckol et al., 1999). Whereas the initial axonal projections formed normally, even in this hard-wired system eliminating activity and $\mathrm{Kv}$ channel overexpression both resulted in later formed ectopic axons that misrouted.

As an initial test for a role of neural activity in RGC axon behavior, we applied Kv current inhibitors to the developing optic projection of Xenopus laevis. This system has been wellcharacterized (Chien and Harris, 1994), and an in vivo exposed brain preparation is available for testing the role of molecules in axon outgrowth (Chien et al., 1993; McFarlane et al., 1995). We report here that the $\mathrm{Kv}$ channel blocker 4-AP, applied to the developing optic projection, impairs axon extension and causes growth cones to grow aberrantly in the optic tract and in their main midbrain target, the optic tectum. These data suggest that $\mathrm{Kv}$ currents regulate the guided growth of RGC axons and raise the possibility that electrical activity is indeed important in this process.

\section{MATERIALS AND METHODS}

Animals. Eggs were obtained from adult Xenopus laevis stimulated to breed by treatment with human chorionic gonadotropin (Sigma, Oakville, Ontario, Canada). Embryos were raised in 10\% Holtfreter's 
solution (Holtfreter, 1943) at $20-25^{\circ} \mathrm{C}$ and staged according to the Nieuwkoop and Faber (1994) staging tables.

Bathing media and ion channel blockers. The exposed brain preparation was performed as described previously (Chien et al., 1993). Briefly, embryos were anesthetized in modified Barth's solution (MBS) supplemented with $0.4 \mathrm{mg} / \mathrm{ml}$ tricaine (ethyl 3-aminobenzoate methanesulfonic acid; Aldrich, Milwaukee, WI), $50 \mathrm{mg} / \mathrm{ml}$ gentamycin sulfate (Sigma), and $10 \mathrm{mg} / \mathrm{ml}$ Phenol Red. The embryos were pinned in a Sylgard dish (Dow Corning, Midland, MI), and the skin and dura over the left brain was removed. This procedure exposes the entire anterior brain on one side, reaching as far caudal as the posterior tectum. Surgery was performed on all embryos before they were randomly divided to develop in either experimental or control solutions for another 18-24 hr until they reached stage 40 . To make the experimental bath solutions, different concentrations of ion channel blockers were used. To block Kv channels, pharmacological inhibitors were added to the control MBS, $\mathrm{pH} 7.4$, solution: 1-4 mM 4-aminopyridine (4-AP; Sigma); 10-40 mM tetraethylammonium chloride (TEA; Sigma); and 20, 40, or $100 \mathrm{~nm} \alpha$-dendrotoxin (Sigma). To block $\mathrm{Na}^{+}$channels TTX (Sigma) was used at $1 \mu \mathrm{M}$, a concentration shown previously to block Xenopus $\mathrm{Na}^{+}$currents (O'Dowd et al., 1988). In one series of experiments the external K concentration was increased from $2 \mathrm{~mm}$ to either 10 or $20 \mathrm{~mm}$ with $\mathrm{KCl}$. In some experiments, embryos were stained after $20 \mathrm{hr}$ with $0.4 \%$ Trypan Blue (Sigma) to label nonviable cells (Worley and Holt, 1996). Blue-labeled cells were counted in the surface neuroepithelium of the telencephalon, diencephalon, and dorsal midbrain of control and treated brains.

Visualization of the optic projection. The optic projection was visualized by anterogradely labeling RGC axons using horseradish peroxidase (HRP; type VI; Sigma). As described previously, the lens of the right eye was surgically removed, and HRP was dissolved in $1 \%$ lysolecithin was placed in the eye cavity (Cornel and Holt, 1992). Embryos were fixed overnight in $4 \%$ paraformaldehyde in $0.1 \mathrm{M}$ sodium phosphate buffer, $\mathrm{pH}$ 7.4. Dissected brains were washed in PBS, reacted with diaminobenzidine (Sigma), dehydrated through a graded series of alcohols, and cleared in 2:1 benzyl benzoate:benzyl alcohol. Whole-mount brains were mounted in Permount (Fisher Scientific, Nepean, Ontario, Canada) under a coverslip supported by two plastic reinforcement rings (Avery Office Products Canada, Bowmanville, Ontario, Canada). The outlines of brains and optic projections were drawn using a camera lucida attachment on a Zeiss microscope. Photographs of preparations were taken using a digital Quantex camera and processed with Adobe Photoshop software.

Quantification of optic projection length and area. The effects of $\mathrm{Kv}$ channel blockers were quantified by measuring the length and area of optic projections in control and treated brains. Camera lucida representations of mounted brains were scanned with an Astra 1200s flatbed scanner (Umax, Freemont, CA) to provide digital images. Samples were used only if they were mounted without significant rolling and had well filled optic projections. Analysis was performed using the public domain NIH Image program. Brains were normalized using previously described macro programs (Chien et al., 1993) by rotating and scaling them to a line drawn between the anterior optic chiasm and the midbrain-hindbrain isthmus (Fig. 1A). This line was matched to a standard reference line, artificially defined as one brain reference unit (BRU); 1 BRU is $\sim 620$ $\mu \mathrm{m}$ in an unfixed brain (Chien et al., 1993). The optic chiasm and the isthmus were chosen as easily identified and reliable morphological markers in the Xenopus brain. The reference line was divided into 0.1 intervals through which concentric circles were drawn. Optic tract length was measured from the optic chiasm to the end of the optic projection containing at least $1 \%$ of RGC axons ( $>10$ axons). The area of brain surface occupied by the optic projection in the ventral diencephalon was also measured. Area measurements were made from the optic chiasm to the 0.4 concentric circle $(\sim 248 \mu \mathrm{m}$ length corresponding to the midoptic tract). The lateral boundaries of the projection were defined by the presence of less than five axons. Unless otherwise stated, samples were compared statistically using a Kruskal-Wallis nonparametric ANOVA test, followed by a Dunn's multiple comparison post hoc test.

Retinal cell cultures. Eye primordia were dissected from stage 24 embryos and cultured as described previously (Harris and Messersmith, 1992). Briefly, dissociated cells or entire eyes were plated onto polyornithine-laminin-coated coverslips in $35 \mathrm{~mm}$ Petri dishes containing $2 \mathrm{ml}$ of culture media. Culture media consisted of 60\% L15 (Life Technologies, Burlington, Ontario, Canada) supplemented with 5\% fetal bovine serum (Life Technologies), $0.5 \%$ gentamycin sulfate (Sigma), and $1 \%$ embryo extract. Explant cultures were used for immunohistochem-
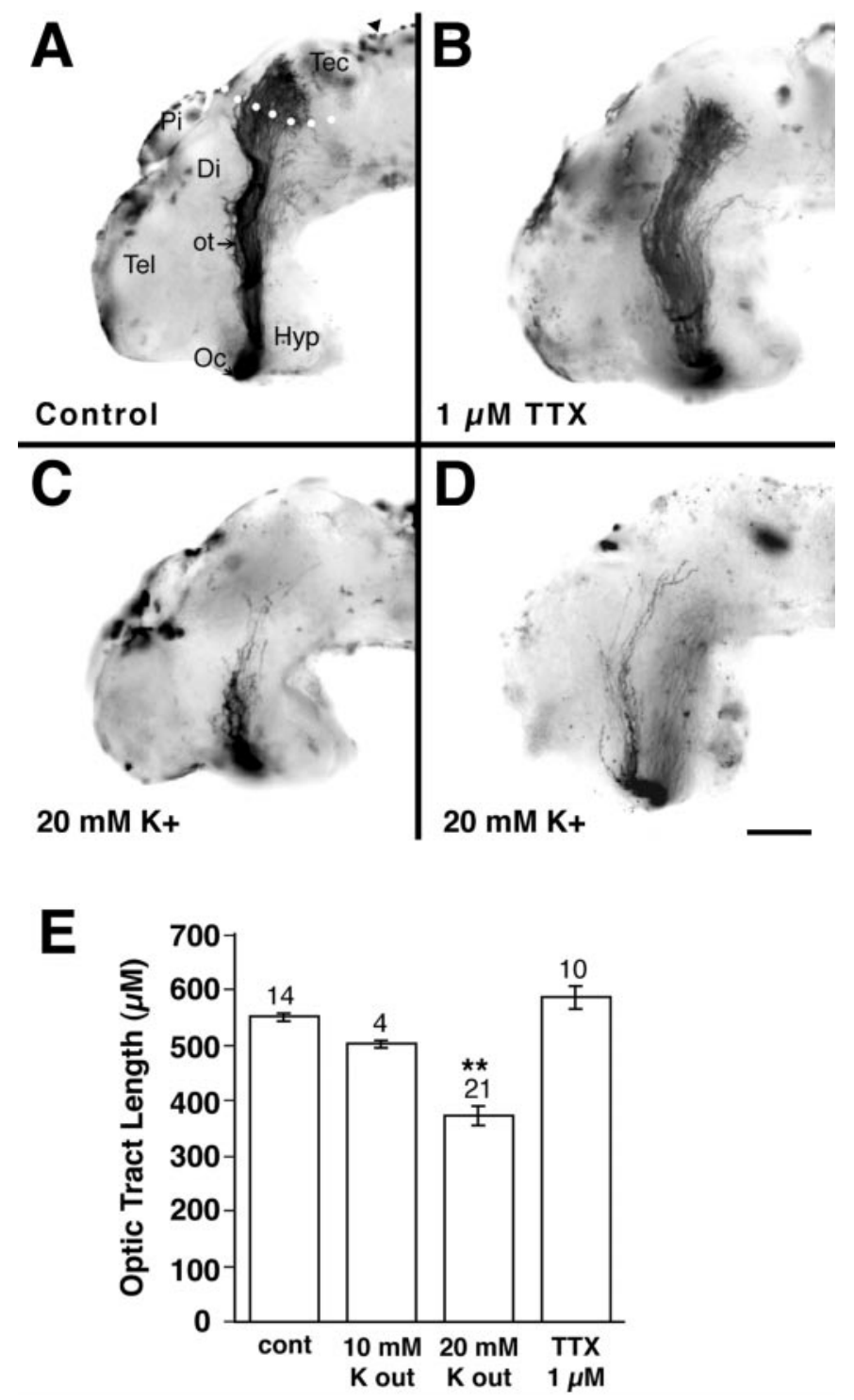

Figure 1. Depolarization shortens the optic projection. $A-D$, Representative examples of stage 40 whole-mount brain preparations showing the HRP-labeled optic projection in a control brain $(A)$ and when $1 \mu \mathrm{M}$ TTX $(B)$ or $20 \mathrm{~mm} \mathrm{KCl}(C, D)$ are applied to the exposed brain. E, Graph showing the optic tract length measured in dehydrated brains. Tract length was measured in normalized BRUs and then converted to micrometers (1 BRU, $\sim 620 \mu \mathrm{m}$; Chien et al., 1993). The optic tract is unaffected by TTX application, but is significantly shorter in brains exposed to depolarizing conditions of external $\mathrm{K}\left({ }^{* *} p<0.01\right)$. Tec, Tectum; $P i$, pineal; Hyp, hypothalamus; $\mathrm{Di}$, diencephalon; Tel, telencephalon; arrowhead, midbrain-hindbrain isthmus; Oc, optic chiasm; ot, optic tract. White dots $(A)$ show the approximate border of the anterior tectum. Scale bar (shown in $D), 100 \mu \mathrm{m}$.

istry, and dissociated cultures were used for neurite length measurements and whole-cell patch-clamp recording.

Neurite length measurements. For neurite measurements, dissociated cells were either grown in control media or media to which was added 1-3 mm 4-AP. After $24 \mathrm{hr}$, cultures were fixed in $0.5 \%$ glutaraldehyde for 45 min. Previously, retinal cells identified as RGCs immunocytochemically were shown to have large phase-bright cell bodies, and one to three long processes (Worley and Holt, 1996). RGCs were viewed using a Nikon Optiphot, connected to a Sony (Tokyo, Japan) video camera and monitor, and the longest unobstructed nerve process was measured.

Immunocytochemistry. Explant cultures were immunostained as described previously (McFarlane et al., 1995) with a rabbit polyclonal 
Figure 2. Developing RGCs express Kv channels. $A, B, \mathrm{Kv}$ currents recorded from two different stage 33/34 equivalent RGCs in culture in the whole-cell configuration (see Materials and Methods). The cells were held at holding potential of $-80 \mathrm{mV}$, and $400 \mathrm{msec}$ voltage steps were applied in $10 \mathrm{mV}$ increments from -60 to $+70 \mathrm{mV}$. In both cells, outward Kv currents are observed that are sensitive to both $3 \mathrm{~mm} 4$-AP and $50 \mathrm{~mm}$ TEA. With the cell shown in $B$, wash out with control solution was able to reverse the blockade. $C-E$, Immunolabeling with a rabbit polyclonal antibody against rat Kv4.3. $C, D$, Transverse sections through stage 33/34 (C) and stage 37/38 (D) retinas showing labeling of cells in the RGC layer. $P E$, Pigment epithelium; $L$, lens; onh, optic nerve head; $m b$, midbrain; $R G C L$, RGC layer; $D$, dorsal; $V$, ventral. $E$, An RGC growth cone in culture immunolabeled with the Kv4.3 antibody. The body of the growth cone, the filopodia, and the lamellopodia are labeled in a punctate fashion. Scale bar (shown in $E$ ): $C, 50 \mu \mathrm{m} ; D$, $25 \mu \mathrm{m} ; E, 5 \mu \mathrm{m}$.
A

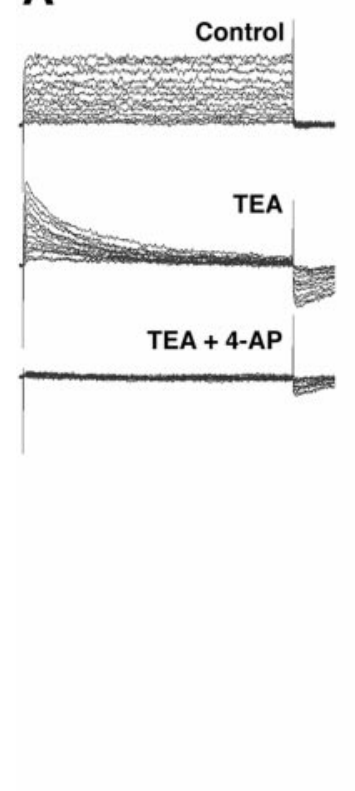

B

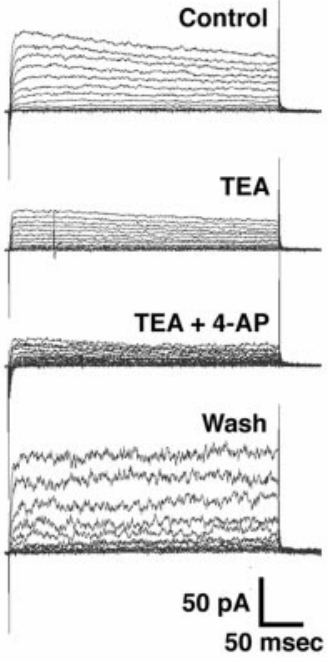

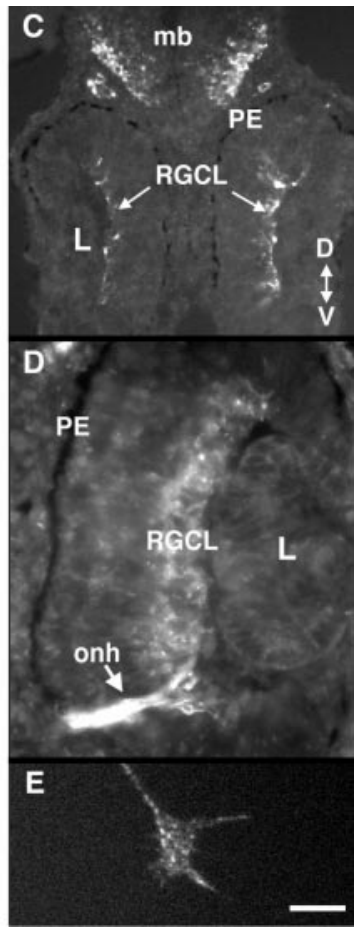

antibody against rat Kv4.3 (Alamone Labs, Jerusalem, Israel) at a dilution of 1:100. The specificity of the antibody for Xenopus Kv4.3 was verified by showing that labeling could be blocked by preincubation with a control peptide against which the antibody was generated (data not shown). The antibody was also used for immunocytochemistry on frozen $12 \mu \mathrm{m}$ transverse sections through the eye of stage 33/34 and stage $37 / 38$ Xenopus embryos (McFarlane et al., 1995). Stage 40 embryos exposed at stage $33 / 34$ to 4 -AP or control solutions were fixed overnight at $4^{\circ} \mathrm{C}$ in $4 \%$ paraformaldehyde for immunocytochemistry. Twelve micrometer frozen transverse sections were cut through the eyes and brain and immunolabeled with mouse monoclonal antibodies against: islet-1 [1:100; Developmental Hybridoma Studies Bank (DSHB)], neural cell adhesion molecule $(N$-CAM) $(6 \mathrm{~F} 11,1: 10$; DSHB), cadherin (1:100; Sigma), 3CB2 (1:10; DSHB), neurofilament (RMO270; 1:1), and Zn-12 (1:10; DSHB). Rabbit polyclonal antibodies were used that recognize pan-trk (1:500) and trkB (1:500) (a kind gift of Dr. D. Kaplan). For immunolabeling of cultures and sections, rhodamine-conjugated secondaries (Jackson Laboratories, West Grove, PA) were used at a dilution of 1:500.

Electrophysiology. Whole-cell currents (Hamill et al., 1981) were obtained at room temperature $\left(20-22^{\circ} \mathrm{C}\right)$ from RGCs in dissociated stage 24 eye cultures grown for $24 \mathrm{hr}$. Recording conditions were as reported by O'Dowd et al. (1988) who recorded voltage-gated currents from cultured Xenopus embryonic spinal cord neurons. Briefly, patch electrodes of 2-5 $\mathrm{M} \Omega$ resistance when filled with intracellular solution were used to establish $\mathrm{G} \Omega$ seals. The pipette solution consisted of (in $\mathrm{mm}$ ): $\mathrm{KCl}, 90$; $\mathrm{KOH}, 3-5$; and HEPES, 4.5; pH-adjusted to 7.4 with $\mathrm{KOH}$. Control perfusion solution consisted of (in $\mathrm{mM}$ ): $\mathrm{NaCl}, 80 ; \mathrm{KCl}, 3$; $\mathrm{CaCl}_{2} .2 \mathrm{H}_{2} \mathrm{O}, 10 ; \mathrm{MgCl}_{2}, 5$; and HEPES, 5; $\mathrm{pH}$ adjusted to 7.4 with $\mathrm{NaOH}$. A Dagan (Minneapolis, MN) 8900 amplifier was interfaced to a AT-style microcomputer by means of a 12 bit Lab Master DMA analogto-digital and digital-to-analog converter (Scientific Solutions Inc., Solon, $\mathrm{OH})$. Data acquisition and generation of voltage-clamp steps were controlled by the pClamp version 5.1 software suite (Axon Instruments, Burlingame, CA). In all experiments, cells were held at $-80 \mathrm{mV}$, and 400 msec voltage steps in $10 \mathrm{mV}$ increments were applied between -60 and $+70 \mathrm{mV}$. Leak substraction was done by means of a $\mathrm{P} /-3$ leak substraction with a temporary holding potential of $-100 \mathrm{mV}$.

\section{RESULTS}

\section{Depolarization shortens the optic projection}

To determine whether the electrical properties of a growth cone influence its motility, we applied pharmacological ion channel blockers to the developing optic projection using a previously described exposed brain preparation (Chien et al., 1993; McFarlane et al., 1995). The skin and dura are removed from one side of the brain of a stage 33/34 embryo, when the first axons from the contralateral eye have crossed the optic chiasm to reach the diencephalon. Optic axons grow close to the pial brain surface and are exposed to the channel blockers over the entire course of their growth through the diencephalon toward their main midbrain target, the optic tectum. Axons are anterogradely labeled at stage 40 , when the majority will have reached the optic tectum in control brains (Fig. 1A). Using this preparation it is possible to determine whether drugs that are known to alter electrical activity affect the extension, pathfinding, and/or target recognition of developing RGC axons.

Initially, to test a role for neural activity in RGC axon outgrowth, we increased the external $\mathrm{K}^{+}$concentration $\left(\left[\mathrm{K}^{+}\right]_{\text {out }}\right)$ in the solution bathing the exposed optic projection. Raising $\left[\mathrm{K}^{+}\right]_{\text {out }}$ is a standard method for depolarizing and thus exciting nerve cells. Increasing $\left[\mathrm{K}^{+}\right]_{\text {out }}$ from 2 to $20 \mathrm{~mm}$ resulted in a shortening of axon length in $62 \%$ (13 of 21) of the optic projections (Fig. $1 C-E)$. The optic projections were on average $33 \%$ shorter than in control embryos (Fig. $1 E$ ). These data support the idea that electrical activity influences the ability of growth cones to extend.

To establish in Xenopus that $\mathrm{Na}^{+}$-dependent spikes are unnecessary for directed extension of a RGC growth cone toward its target (Harris, 1980; Stuermer et al., 1990), we blocked $\mathrm{Na}^{+}$dependent APs with $1 \mu \mathrm{M}$ TTX. Our data indicate that TTX treatment had no effect on the outgrowth of retinal axons: TTXtreated optic projections $(n=10)$ resembled those in control embryos $(n=14)$ (Fig. $1 B, E)$. Thus, as in other species, RGC growth cones do not require $\mathrm{Na}$-dependent APs to extend to their target.

\section{RGCs and their growth cones express Kv channels}

Many developing neurons, however, exhibit subthreshold depolarizations before they are able to produce regenerative APs (Ribera and Spitzer, 1992), raising the possibility that TTX- 

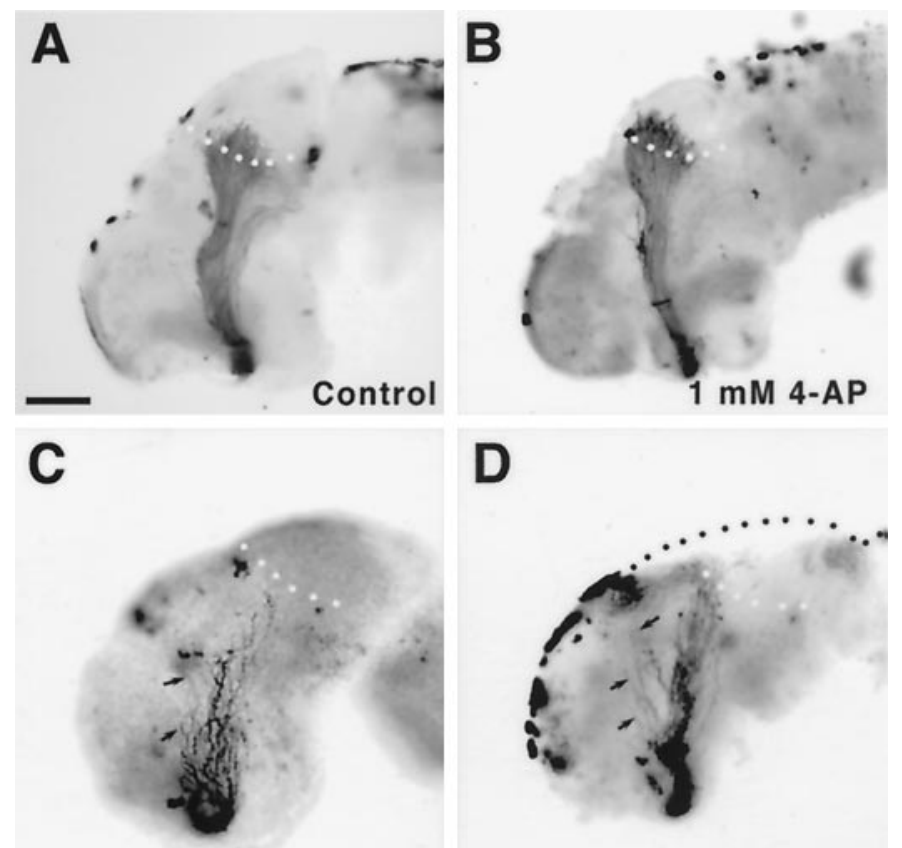

$3 \mathrm{mM}$ 4-AP

$3 \mathrm{mM} 4-\mathrm{AP}$
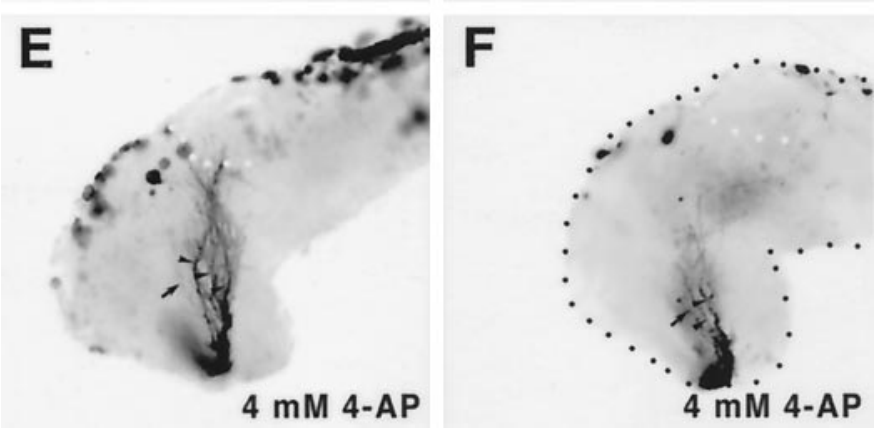

Figure 3. 4-AP disrupts the optic projection. $A-F$, Whole-mount brain preparations showing HRP-labeled optic projections in control $(A)$ and 4-AP-treated $(B-F)$ brains. At a low concentration of 4-AP of $1 \mathrm{~mm}(B)$, optic axons behave normally. Optic projections exposed to higher levels of 4-AP, $3 \mathrm{~mm}(C, D)$ and $4 \mathrm{~mm}(E, F)$, are shorter than control, appear defasciculated (arrowheads), and have many axons that grow aberrantly away from the optic tract (arrows). Scale bar (shown in $A$ ), $100 \mu \mathrm{m}$.

insensitive depolarizing events could be occurring in growth cones. One method for altering subthreshold depolarizations is to block the activity of Kv channels in the membrane. Altering $\mathrm{Kv}$ channel function has proven useful in revealing the cellular processes that are regulated by excitability (for review, see Ribera and Spitzer, 1992). Before examining the effects of specific Kv channel blockers on the extension and guidance of optic axons, we first determined whether RGCs express Kv channels at the stage when their axons are growing out to the optic tectum. Two methods were used to verify the presence of Kv channels.

\section{Electrophysiology}

To isolate RGC somata we dissociated stage 24 eye primordium, before RGCs have initiated axons, and plated the cells on laminin-polyornithine-coated coverslips. Because cells at this stage are held together by $\mathrm{Ca}^{2+}$-dependent adhesions, dissociation is relatively mild and involves leaving the primordia for 20 min in a low- $\mathrm{Ca}^{2+}$ media. RGC Kv currents were recorded using the whole-cell patch-clamp technique after $20-28 \mathrm{hr}$ in culture
(Fig. 2A,B). Stage 24 embryos, allowed to develop at the same temperature as the cultures, were between stages 32-35/36 during the recording period. At this stage in vivo, $\mathrm{RGC}$ axons are extending through the ventral brain. RGCs in culture were identified based on previously described criteria as cells with large, phase-bright somata and one to three long nerve processes (Worley and Holt, 1996). All RGCs (26 of 26) from which we recorded expressed voltage-dependent outward currents: all RGCs had a sustained outward current, and $81 \%$ had a rapidly inactivating outward current. These currents were partially or wholly blocked by the classical Kv current inhibitors 4-AP and TEA (Fig. 2A,B).

\section{Immunocytochemistry}

Kv channel expression was examined at the protein level by immunolabeling eye cross sections with a polyclonal antibody against rat Kv4.3. Several $\mathrm{Kv}$ channels have been cloned in $\mathrm{Xe}$ nopus and include Kv1.1, Kv1.2, Kv2.1, Kv2.2, and Kv4.3 (Ribera and Nguyen, 1993; Burger and Ribera, 1996; Lautermilch and Spitzer, 1997). We found Kv4.3 was expressed in developing Xenopus RGCs at the time their axons grow into the contralateral brain (stage 33/34) (Fig. 2C). This is especially clear in a stage $37 / 38$ eye where the RGC layer is labeled and so is the optic nerve head and optic nerve (Fig. 2D). Moreover, the Kv4.3 antibody stains RGC growth cones in culture in a punctate fashion (Fig. $2 E$ ). The cloned Xenopus Kv4.3 is sensitive to both 4-AP and TEA (Lautermilch and Spitzer, 1997). In situ hybridization with digoxygenin-labeled antisense probes for Kv1.1 and Kv2.2 indicate that these channel subtypes are not expressed in the developing Xenopus retina (data not shown). The electrophysiological and immunocytochemical results strongly suggest that developing RGCs and their axons express $\mathrm{Kv}$ channels when the axons are extending through the brain.

\section{Inhibiting Kv currents disrupts the optic projection}

To inhibit $\mathrm{Kv}$ channels we used 4-AP in the exposed brain preparation. 4-AP application had a dose-dependent effect on both the extension and the guidance of optic fibers. RGC axons were unaffected by low concentrations of 4-AP (1 mM) with the optic projections resembling those of control embryos (Fig. 3A, $B$ ). At higher concentrations of 4-AP (3 and $4 \mathrm{~mm}$ ), however, $70 \%$ (24 of 34 ) and $88 \%$ (21 of 24) of the optic projections, respectively, showed some abnormality as compared to only 5\% (1 of 22) in control (Fig. $3 C-F$ ). The Kv currents we recorded in developing RGC somata showed a similar sensitivity to 4-AP. Three main disruptions of the optic projections were observed.

(1) Projections treated with 3 and $4 \mathrm{~mm} 4$-AP were 85 and $67 \%$ of the length of control projections, respectively (Figs. $3 C, F, 5 A$ ). These results suggest that blocking $\mathrm{Kv}$ channels has a significant inhibitory effect on axon growth. Interestingly, whereas $3 \mathrm{~mm}$ 4-AP had a small inhibitory effect on extension, many fewer axons innervated the optic tectum than in control (compare the number of axons in the target in Fig. $3 A$ with the numbers in $3 D$ and $3 E$ ). The relative scarcity of innervating axons was attributable to the fact that trajectories of RGC axons were frequently aberrant (see below).

(2) The behavior of many axons in the diencephalon was erratic, resulting in a considerably more disorganized projection than in control (Fig. 4). This disorganization took two forms. First, in $3 \mathrm{~mm} 4$-AP-treated brains the optic projection appeared defasciculated in $35 \%$ (12 of 34) of the cases (Fig. $4 C-F$ ), a phenomenon that was not observed in control embryos (Fig. $4 A, B)$. Second, in almost $40 \%$ (13 of 34 ) of the $3 \mathrm{~mm} 4$-AP- 

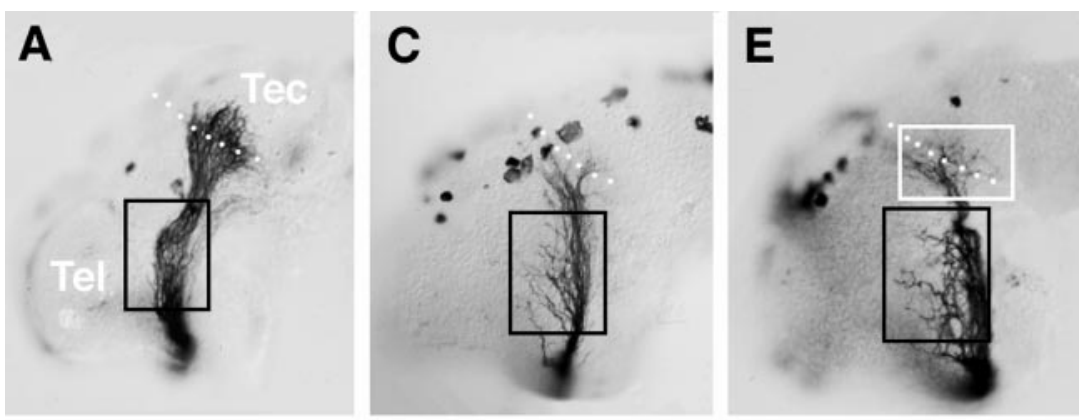

Figure 4. Misrouting of 4-AP-treated axons. Nomarski images of HRP-labeled optic projections in control and 3 mM 4-AP-treated brains. $A, B$, In control, axons grow tightly together in the optic tract as seen at both low $(A)$ and higher $(B)$ magnification. $C-F$, In contrast, in optic projections exposed to $3 \mathrm{~mm}$ 4-AP many axons behave aberrantly. $D$ and $F$ are higher power views of areas boxed in black in $C$ and $E$, respectively. In both cases, the optic projection appears defasciculated. Moreover, many axons grow aberrantly into regions they normally avoid (arrows). White boxed area represents target area shown at higher power magnification in Figure 6. White dots show the approximate anterior border of the optic tectum. Scale bar (shown in $F$ ): $A, C, E, 200 \mu \mathrm{m} ; B, D, F, 40 \mu \mathrm{m}$.
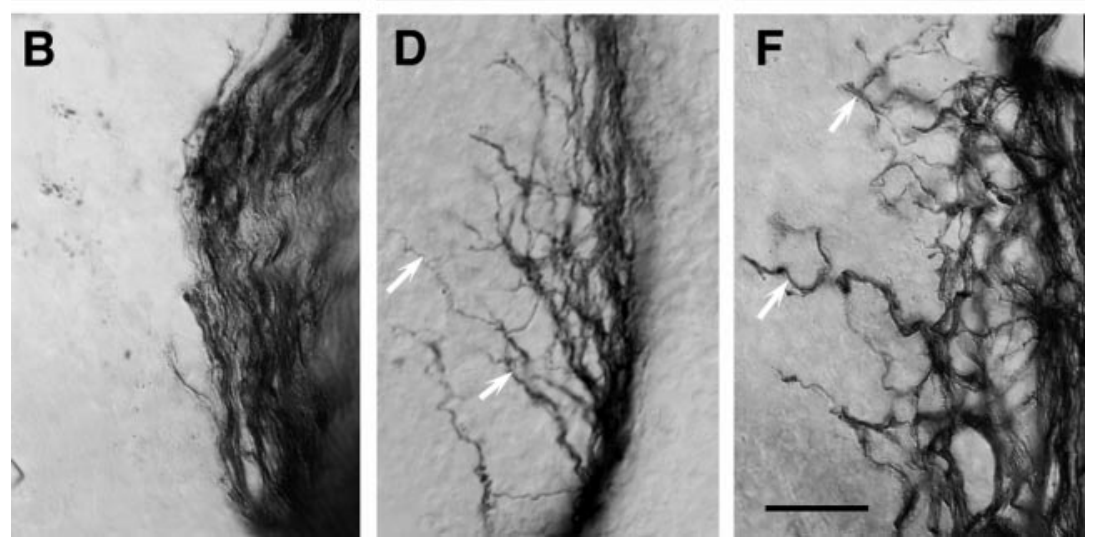

treated brains, axons left the optic tract and grew aberrantly in the diencephalon/telencephalon (Fig. 4D,F). Occasionally these misrouted axons extended orthogonally into the depth of the neuroepithelium (data not shown). To quantify the disruption of the optic projection, the area of the brain surface covered by the projection was measured between the optic chiasm and the mi-

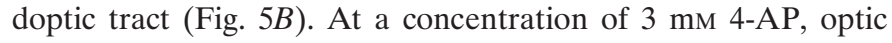
projections covered a $50 \%$ greater area than in control brains, indicating that there was disruption of the normally tightly organized optic tract and that RGC axons were misrouting into areas where they would not normally grow.

(3) Axons that did reach the target by stage 40 showed aberrant innervating behavior (Fig. 6). In control, except in one case where the fibers were shorter than normal, axons grew into the optic tectum in a directed fashion and then branched and arborized in the anterior tectum (Fig. 6A,C). In contrast, in $41 \%$ (9 of 22) of $3 \mathrm{~mm}$ 4-AP-treated optic projections, RGC axons reaching the target area failed to innervate it appropriately (Fig. 6B,D,F). Defects included optic fibers diving orthogonally into the depth of the tectal neuroepithelium, changing course abruptly, meandering, or failing to enter the optic tectum entirely. The targeting defect is particularly clear in an earlier stage $37 / 38$ brain, a stage when normally fewer axons have reached the optic tectum. In control, the first RGC axons are just innervating the tectum (Fig. $6 A$ ), whereas in the $3 \mathrm{~mm} 4$-AP-treated brain, axons turn to avoid the target (Fig. 6B).

\section{Site of action of 4-AP may be at RGC growth cones}

4-AP could be affecting the extension and guidance of RGC axons by directly altering growth cone Kv channels or by indirect actions on the neuroepithelium through which RGC axons extend. To test the possibility that 4-AP could be acting on RGC growth cones directly we examined whether 4-AP: (1) affected retinal neurite outgrowth in culture, where there is no neuroepithelial substrate on which 4-AP could act. We treated dissociated stage 24 retinal cultures with varying concentrations of 4-AP for
$24 \mathrm{hr}$, and measured the longest neurite of cells with large, phase-bright soma and 1-3 main processes. 4-AP had a dosedependent inhibitory effect on the length of retinal neurites, indicating that this $\mathrm{Kv}$ channel blocker may directly alter growth cone motility (Fig. 7A). 4-AP-treated growth cones were considerably smaller than control growth cones and had fewer filopodia (Fig. 7B,C), which might account for the shortness of the 4-APtreated neurites. Slightly lower concentrations were needed in culture to impair axon extension than in vivo, presumably because in the live brain 4-AP has to gain access to RGC axons growing 2-10 $\mu \mathrm{m}$ below the pial surface; or (2) obviously altered the patterning or morphology of the neuroepithelium through which the axons extend. To examine this possibility, we performed immunolabeling of control and 4-AP-treated brains with several neuroepithelial cell markers, four of which are shown in Figure 8. These included antibodies that recognize: (1) general neuronal markers such as $\mathrm{Zn}-12$ (Fig. 8A,B; Metcalfe et al., 1990) and neurofilament (RMO 270); (2) radial glial cells (Fig. 8F; 3CB2; Prada et al., 1995); (3) putative guidance molecules such as $N$-CAM and $N$-Cadherin (Riehl et al., 1996). In dorsal root ganglion neurons $\mathrm{N}$-Cadherin levels are downregulated by neuronal firing (Itoh et al., 1997); (4) neurotrophin receptor tryosine kinases (trks). Pan-trk (Fig. $8 D, E$ ) and trkB antibodies were tested because membrane depolarization regulates trkB expression in neurons (Tongiorgi et al., 1997; Meyer-Franke et al., 1998); and (5) islet-1, a lim homeodomain protein that is expressed by ventrally positioned motoneurons in the forebrain, to investigate whether dorsal-ventral polarity was affected (Fig. 8C; Ericson et al., 1995). None of these markers showed an obvious difference in the intensity or pattern of expression between the control and 4-AP-treated brains, suggesting that 4-AP treatment has no gross effect on the patterning of the neuroepithelium. To further test the integrity of the neuroepithelium we performed a trypan blue exclusion assay. Trypan blue is excluded from viable cells and is therefore useful as a marker of dead neuroepithelial 
A

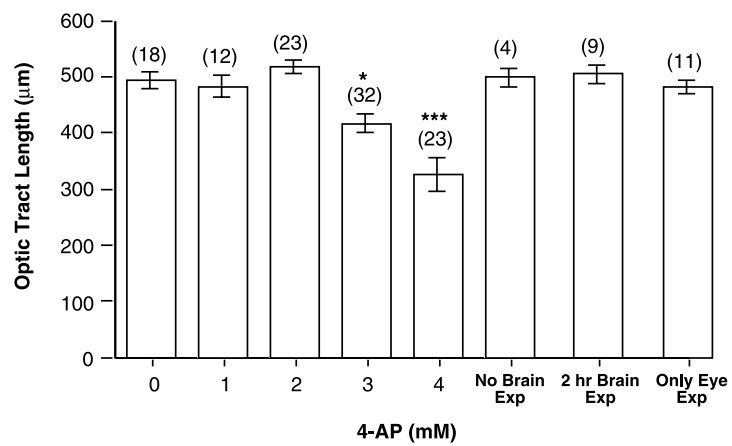

B

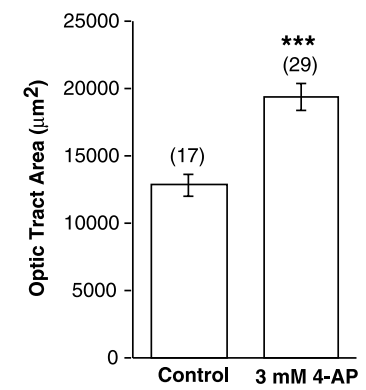

Figure 5. 4-AP impairs RGC extension and pathfinding. Quantitation of the effects of 4-AP on the developing optic projection. Control and treated brains were exposed at stage 33/34 and fixed at stage 40. Camera lucida representations were made of the brain and optic projection, normalized, and two features of the optic projection were measured: length and area of brain covered. $A$, Dose-response curve showing the effect on optic tract length (in micrometers) of increasing doses of 4-AP. Also shown are the measurements of optic tract length for embryos treated with $3 \mathrm{~mm}$ 4-AP but where: (1) the brain was not exposed (No Brain Exp); (2) the brain was exposed to a $2 \mathrm{hr}$ pulse of 4-AP (2 $\mathrm{hr}$ Brain Exp), and (3) the brain was not exposed, but the lens was removed from the contralateral eye at stage 33/34, exposing the underlying RGC somata to 4-AP (Only Eye Exp). Only continuous exposure of the growing RGC axons to 4-AP had a significant effect on the length of the optic projection. $B$, The mean area of the surface of the forebrain covered by the optic tract, as measured between the optic chiasm (0 BRU) and the midoptic tract (0.4 BRU), is shown for control and $3 \mathrm{~mm}$ 4-AP-treated brains. The optic tract covers a significantly greater area of the ventral diencephalon than in control. Numbers of animals are shown in parentheses. Error bars indicate SEM $\left({ }^{*} p<0.05 ;{ }^{* *} p<0.01 ;{ }^{* * *} p<0.001\right.$; for $B$ the nonparametric Mann-Whitney $U$ test was used).

cells (Worley and Holt, 1996). Similar numbers of trypan bluepositive cells $(p>0.5)$ were present in the surface forebrain and midbrain neuroepithelium of control $(24.9 \pm 4$, SEM; $n=16)$ and 3 mM 4-AP $(18.6 \pm 3, \mathrm{SEM} ; n=18)$-treated brains. These results suggest that extensive cell death was not occurring in 4-APexposed brains.

Taken together, the culture and immunocytochemistry data raise the possibility that it is $\mathrm{Kv}$ channel activity in the growth cone that is important for axon extension and guidance in vivo.

\section{Inhibiting soma Kv channels does not affect growth cone motility}

Our electrophysiological data suggest that all stage 33/34 RGCs express Kv currents. Given that Kv channels modulate membrane depolarizations it is possible that 4-AP exerts its effects by altering electrical impulses coming from the soma. To test this possibility, 4-AP was applied selectively to RGC somata. The lens was removed from the right eye at stage 33/34 to expose the RGCs, which are directly underneath the lens, to $3 \mathrm{~mm} 4$-AP. Exposing RGC soma, but not their axons, to 4-AP had no effect on the optic
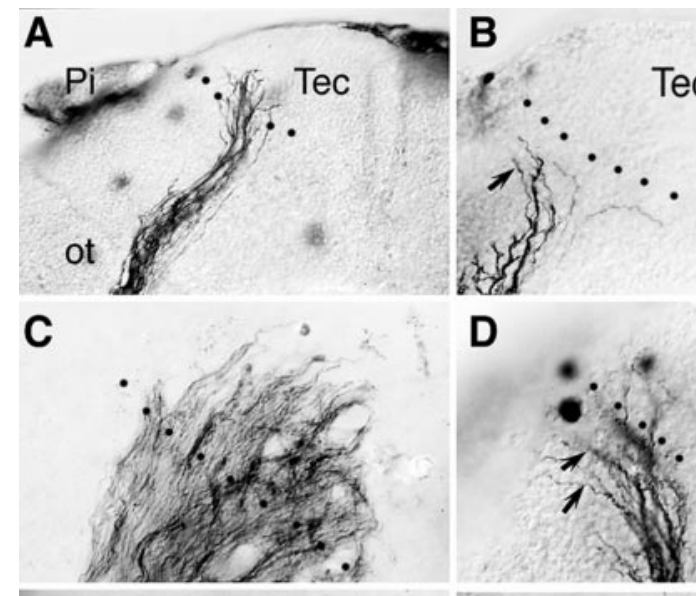

D

E

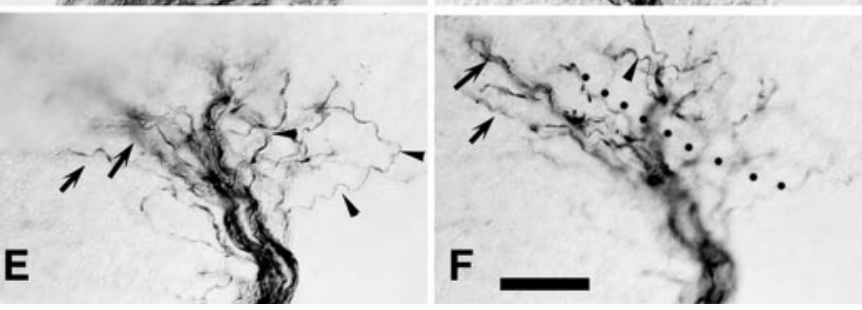

Figure 6. Mistargeting of 4-AP-treated axons. Nomarski images of control $(A, C)$ and 4-AP treated $(B, D-F)$ HRP-labeled optic projections. $A$, $B$, Control $(A)$ and $3 \mathrm{~mm} 4$-AP-treated $(B)$ stage $37 / 38$ optic projections. The first axons have grown into the optic tectum in control, but turn and avoid the optic tectum in the 4-AP-treated brain (arrow). $C-F$, Optic projections in the target region of stage 40 embryos. In control, the axons grow into the optic tectum in an orderly manner and begin arborizing $(C$; Fig. $4 A)$. Whereas, in 4-AP-treated brains $(D-F)$, axons either fail to enter the optic tectum (arrows) or grow into the target and then grow in an apparently random fashion (arrowheads). $E$ and $F$ are high-power views of different focal planes of the white-boxed area in Figure $4 E$. $P i$, Pineal gland; Tec, optic tectum; ot, optic tract. Scale bar (shown in $F$ ): $A, B, 100$ $\mu \mathrm{m} ; D-F, 25 \mu \mathrm{m}$. Dotted black lines indicate the approximate anterior border of the optic tectum.

projection in terms of length (Fig. $5 A$ ) or area (data not shown). These data indicate that 4-AP is not acting by modulating electrical events originating from the RGC soma.

\section{The Kv channel blocker TEA has similar effects to 4-AP on axon extension}

To test the specificity of the 4-AP effect for Kv channel blockade, we treated the optic projection with two additional $\mathrm{Kv}$ channel blockers (Fig. 9). TEA is a nonspecific Kv channel blocker that blocks many different $\mathrm{Kv}$ channels. TEA at a concentration of 30-40 mM had a dramatic effect on growing optic axons, but had no effect on the viability of the neuroepithelium as determined by the trypan blue exclusion assay (data not shown). Cloned Xenopus Kv channels (Ribera and Nguyen, 1993; Burger and Ribera, 1996) and the Kv currents we recorded in RGC somata show a similar TEA sensitivity. TEA influenced axon extension causing a dose-dependent decrease in the length of the optic axons (Fig. $9 E$ ) so that at a concentration of $30 \mathrm{~mm}$ TEA the majority of stage 40 optic projections $(67 \%, 16$ of 24$)$ were shorter than control (on average $61 \%$ the length). Interestingly, in contrast to the guidance defects observed with 4-AP, TEA only seems to impair axon extension. We also used $\alpha$-dendrotoxin, a specific blocker of Kv1.1 and 1.2 channels (Harvey, 1997). $\alpha$-dendrotoxin had no effect on the growth or guidance of RGC axons even at concentrations up to $100 \mathrm{~nm}(n=8)$ (Fig. $9 E)$, which is effective at 
A

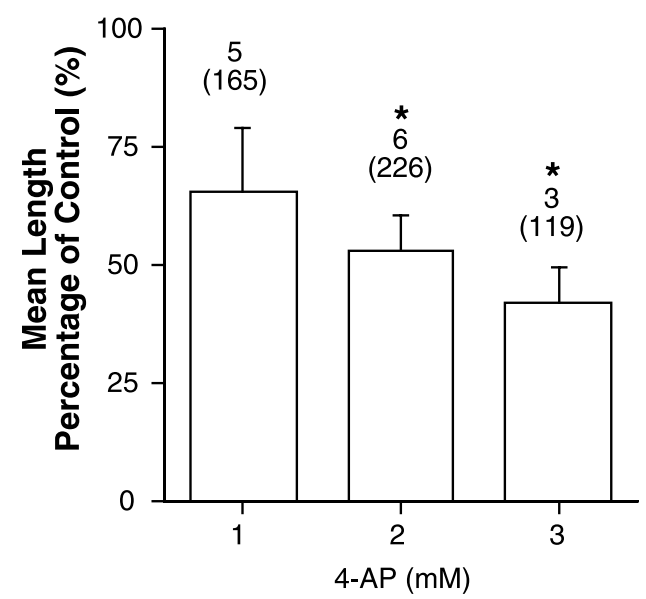

B

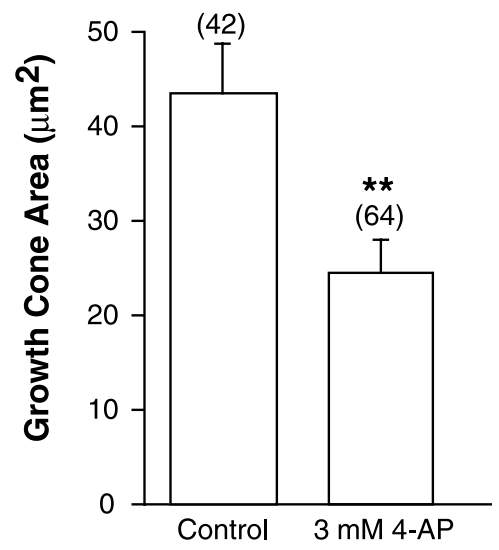

C

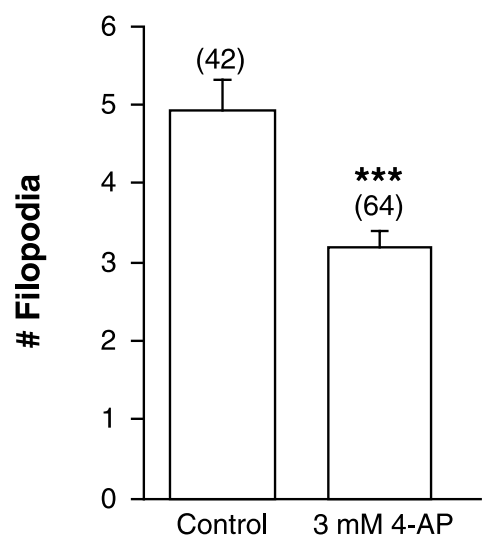

Figure 7. 4-AP directly impairs axon extension in culture. A, Graph showing the mean length of the longest neurite of retinal cells treated with 1,2 , or $3 \mathrm{~mm} 4-\mathrm{AP}$ as a percentage of the mean length in sister control cultures. Numbers above parentheses are the number of separate experiments, whereas the amount in the parentheses represents the number of neurites measured. Error bars indicate SEM ${ }^{*} p<0.05$; unpaired ANOVA; Dunnett's post hoc analysis). B, Graph showing the mean area of the growth cones of retinal cells treated with 3 or $4 \mathrm{~mm} \mathrm{4-AP}$ as compared to control growth cones. Growth cone area consisted of the area occupied by the lamellopodia and growth cone body $(* * p<0.01$, two-tailed Student's $t$ test). $C$, Graph showing the mean number of filopodia of control and $3 \mathrm{~mm}$ 4-AP-treated growth cones. Numbers in parentheses are the number of growth cones analyzed $\left({ }^{* * *} p<0.001\right.$; Mann-Whitney $U$ test). Data in $B$ and $C$ are from one experimental set, although similar results were observed in two additional independent trials.
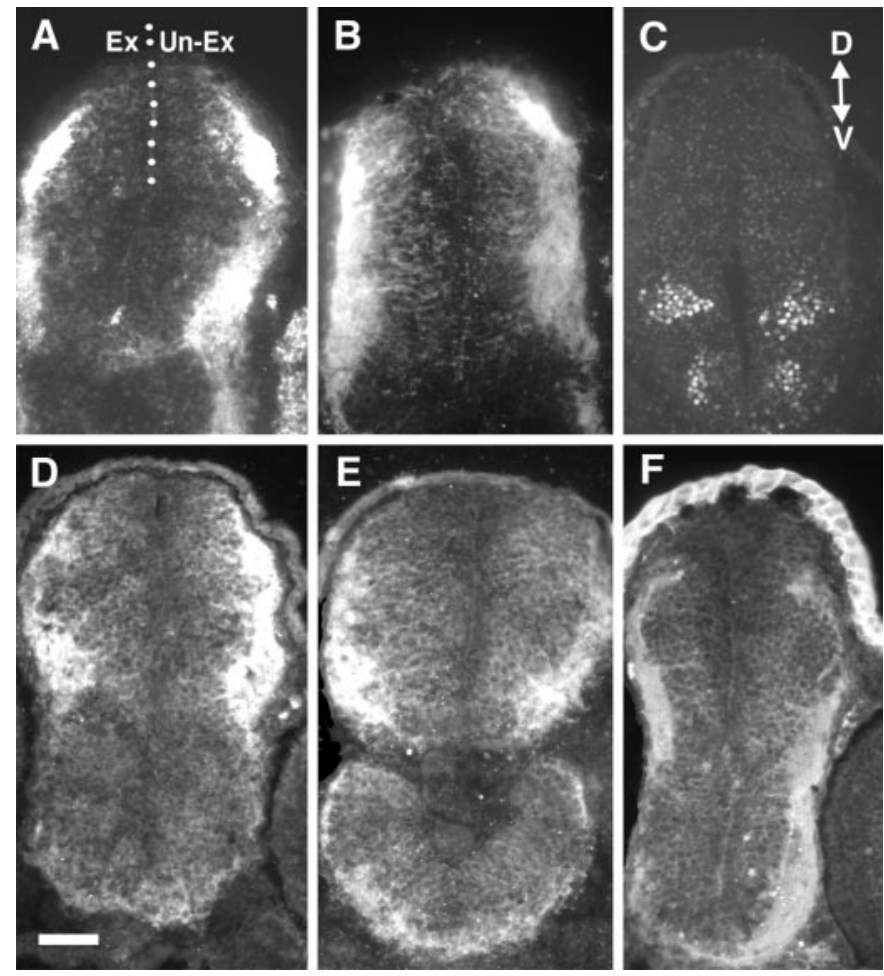

Figure 8. 4-AP treatment does not grossly affect the patterning or morphology of the neuroepithelium. Cross sections through the diencephalon/midbrain regions of stage 40 embryos exposed at stage 33/34 to control or $3 \mathrm{~mm} 4$-AP bathing solutions. In all panels the exposed $(E x)$ side of the brain is on the left, and the unexposed $(U n-E x)$ side is on the right. Sections were immunolabeled with markers of the neuroepithelium. $A, B, \mathrm{Zn}-12$ immunolabeling of control $(A)$ and 4-AP $(B)$-exposed brains. $C$, Islet-1 immunolabeling of ventral neurons in a 4-AP-treated brain showing that dorsal ventral polarity is maintained. $D, E$, Immunolabeling of control $(D)$ and 4-AP $(E)$-treated brains with a rabbit polyclonal pan-trk antibody. $F$, Immunolabeling of a 4-AP-treated brain with a radial glial cell marker (3CB2). $D$, Dorsal; $V$, ventral. Scale bar (shown in $D), 100 \mu \mathrm{m}$.

blocking certain Xenopus Kv channels (Brau et al., 1990). This result is not surprising given that, as we and others have determined, neither channel is expressed in the developing Xenopus eye (Ribera, 1990; Ribera and Nguyen, 1993).

\section{DISCUSSION}

In this paper we show that inhibiting $\mathrm{Kv}$ channels affects the ability of RGC axons to extend in culture and causes extension and pathfinding defects of the axons in vivo. Specifically, we report that pharmacological $\mathrm{Kv}$ channel blockers inhibit axon extension, and, in the case of 4-AP, result in guidance defects. These data support a role for $\mathrm{Kv}$ channels in modulating the directed growth of RGC axons. The observation that depolarizing $\mathrm{RGC}$ axons with high $\left[\mathrm{K}^{+}\right]_{\text {out }}$ inhibited axon extension in vivo suggests that electrical activity influences the initial formation of the optic projection and raises the possibility that $\mathrm{Kv}$ channels participate in this regulation.

Although no axon guidance defects have been reported in Drosophila Kv channel null mutants (Burg and Wu, 1989), these data do not exclude a role for $\mathrm{Kv}$ channels in axon guidance. Given the large number of different $\mathrm{Kv}$ channel genes, it is quite likely that redundancy exists, such that eliminating one Kv channel at a time has no axon guidance phenotype. Furthermore, it is known that modulation of one Kv channel can result in compen- 


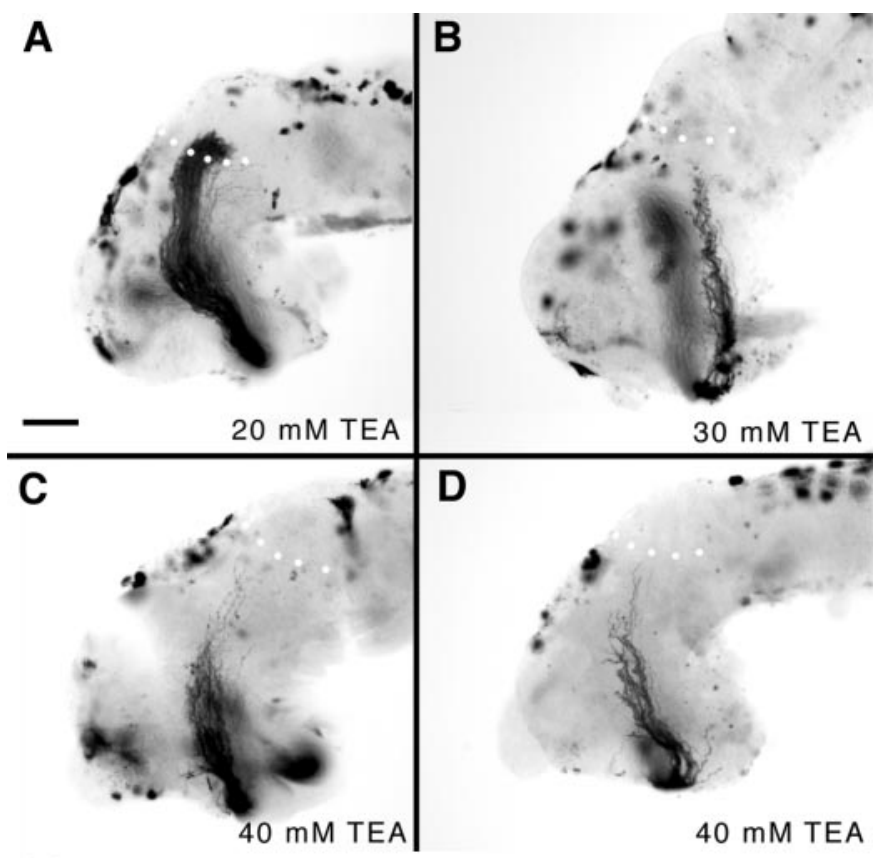

E

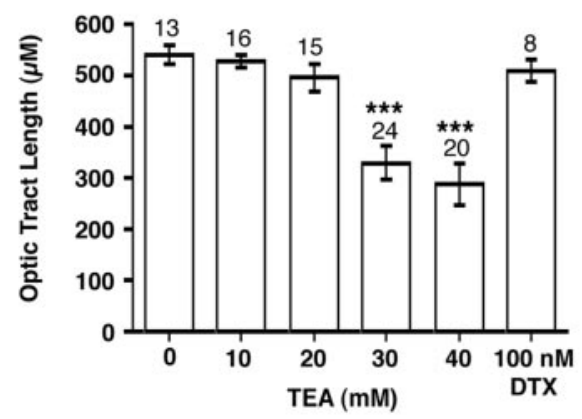

Figure 9. TEA treatment inhibits growing RGC axons. $A-D$, HRPlabeled optic projections in stage 40 whole-mount brains exposed at stage $33 / 34$ to $20 \mathrm{~mm}(A), 30 \mathrm{~mm}(B)$, and $40 \mathrm{~mm}(C, D)$ TEA. Increasing concentrations of TEA result in shorter optic projections, but no obvious pathfinding or fasciculation errors. Scale bar (shown in $A$ ), $100 \mu \mathrm{m}$. E, Graph showing the mean optic tract length (converted to micrometers from BRUs) with increasing doses of TEA. Low concentrations of TEA $(10-20 \mathrm{~mm})$ had little or no effect on the optic projection, whereas the optic tract was significantly shorter in brains exposed to either 30 or $40 \mathrm{~mm}$ TEA $(* * * p<0.001)$. $\alpha$-dendrotoxin at a concentration of $100 \mathrm{~nm}$ had no effect on the extension of optic axons $(p>0.5)$. Numbers above bars represent numbers of embryos.

satory changes in other Kv channels (Barry et al., 1998). We were able to reveal a function for $\mathrm{Kv}$ channels in our assay possibly because of the more general nature of the pharmacological blockade.

We propose that the Kv channel blockers are affecting growth cones directly. We cannot rule out the possibility, however, that blockers applied to the developing optic projection could be affecting neuroepithelial cells to cause the axon defects. For example, aberrant axonal behavior could result if inhibiting $\mathrm{Kv}$ channels altered the electrical activity of brain cells because activity is known to regulate the expression of extrinsic cues such as CAMs and growth factors (Cohen-Cory and Fraser, 1995; Itoh et al., 1997; Tongiorgi et al., 1997). This would imply that careful regulation of electrical activity in the developing brain is critical for normal patterning of extrinsic cues involved in axon guidance. Although we find this possibility of great interest, we believe our data points more readily to the defects being axon- rather than substrate-based. Several pieces of evidence support the idea that the 4-AP actions are axon-based. First, the viability of the neuroepithelium and the expression of several markers were not obviously modified by 4-AP. Second, 4-AP impaired the extension of RGC axons growing on a simple culture substrate, suggesting that this blocker could directly affect growth cone motility. Finally, we showed that developing RGCs axons express at least one Kv channel, Kv4.3, which in Xenopus is highly 4-APsensitive (Lautermilch and Spitzer, 1997).

Culture studies suggest a role for neural activity in regulating growth cone motility (Neely and Nicholls, 1995). Developing RGCs are electrically active before the processing of visual information at birth (Robinson and Wang, 1998). Previous studies have implicated $\mathrm{Na}^{+}$-dependent APs in synaptic rearrangements in the developing visual system (Shatz, 1990). TTX inhibited the refinement of the tectal topographic map of regenerating and developing goldfish RGC axons (Schmidt et al., 1983; Schmidt and Buzzard, 1993; Olson and Meyer, 1994) and in kittens the ocular segregation of RGC inputs in the target lateral geniculate nucleus (LGN) (Sretavan et al., 1988). The absence of RGC projection defects after TTX application in several vertebrate species, including Xenopus, strongly supports the idea that $\mathrm{Na}^{+}$-dependent APs play no role in the growth of RGC fibers (Harris, 1980; Schmidt et al., 1983; Sretavan et al., 1988; Stuermer et al., 1990; this study). Interestingly, TTX injection into the brain caused failure of a population of LGN axons to enter the kitten visual cortex (Catalano and Shatz, 1998), indicating that $\mathrm{Na}^{+}{ }_{-}$ dependent APs play a later role in guiding axons in this system.

It is likely that several $\mathrm{Na}^{+}$-independent mechanisms function in developing RGCs and their growth cones to change membrane potential (Robinson and Wang, 1998). $\mathrm{Ca}^{2+}$-dependent spikes and neurotransmitter-evoked depolarizations have been reported in the developing eyes of various vertebrate species (Sakaguchi et al., 1984; Skaliora et al., 1993; Yamashita and Fukuda, 1993; Wong, 1995). In chick retina, $\mathrm{Ca}^{2+}$ transients are observed before synapse formation (Catsicas et al., 1998), and undifferentiated cells express L-type $\mathrm{Ca}^{2+}$ channels (Yamashita and Fukuda, 1993). Moreover, the majority of mouse and cat RGCs express Kv currents soon after birth, before the cells have the ability to generate spontaneous APs (Rorig and Grantyn, 1994; Skaliora et al., 1995). Our electrophysiological recordings indicate the presence of pharmacologically and kinetically distinct outward currents in developing RGC somas, suggesting that growth cones express more than one Kv channel type. Possibly 4-AP is acting on Kv4.3 channels, which are sensitive to 4-AP and are expressed in developing Xenopus RGC growth cones (Lautermilch and Spitzer, 1997).

Our data indicate that blocking Kv channels with 4-AP impairs axon extension, but more interestingly causes misrouting of axons. We propose that 4-AP acts at the growth cone, because axon outgrowth was unaffected by 4-AP applied to the soma, even though RGCs at equivalent ages in culture express 4-AP-sensitive outward currents. This idea is supported by the fact that RGC axons removed from their soma can navigate appropriately through the diencephalon (Harris et al., 1987), that TTXblockade has no effect on RGC axon outgrowth in vivo, and that in Xenopus spinal neurons, growth cone-generated $\mathrm{Ca}^{2+}$ waves regulate motility (Spitzer et al., 1995; Gomez and Spitzer, 1999). How might Kv channels be exerting their effects on RGC growth cone behavior? Conceivably, Kv channels may function in the downstream transduction of an extrinsic cue. For instance, CAMs 
modulate Kv channels in glial precursor and neuroblastoma cells (Sontheimer et al., 1991; Arcangeli et al., 1993). More likely, Kv channels influence motility by affecting the electrical excitability of the growth cone. Membrane depolarization, possibly initiated by the action of extrinsic cues, would activate Kv channels. The resulting hyperpolarizing current would effectively shunt out the depolarization and return the membrane potential to rest. Thus, $\mathrm{Kv}$ channels may function to rapidly silence the growth cone after electrical activation. In vitro studies indicate that membrane potential can modulate growth cone motility by regulating $\mathrm{Ca}^{2+}$ influx through voltage-gated $\mathrm{Ca}^{2+}$ channels (Gottmann and Lux, 1995; Neely and Nicholls, 1995; Lnenicka et al., 1998). $\left[\mathrm{Ca}^{2+}\right]_{\mathrm{i}}$ is a major modulator of growth cone motility both in vitro and in vivo (Kater and Mills, 1991; Kater et al., 1994; Gomez and Spitzer, 1999). A similar mechanism could be invoked to explain the RGC axon defects seen with Kv channel blockade, a manipulation we hypothesize makes growth cones electrically more excitable by removal of the Kv current shunt. Indeed, depolarizing RGC axons with high $\mathrm{K}^{+}$caused similar extension defects as those observed with 4-AP and TEA treatment. Thus, one model for the function of growth cone $\mathrm{Kv}$ channels is to suppress $\mathrm{Ca}^{2+}$ entry, thereby keeping $\left[\mathrm{Ca}^{2+}\right]_{\mathrm{i}}$ low and maintaining the growth cone in a motile state.

Although it is likely that $\mathrm{Kv}$ channels regulate growth cone motility by modulating $\left[\mathrm{Ca}^{2+}\right]_{i}$, an intriguing alternate possibility is that they more selectively affect axons by influencing responsiveness to environmental cues whose signal transduction mechanism is dependent on membrane potential. For instance, CAMstimulated neurite outgrowth of rat cerebellar and chick ciliary ganglion neurons is inhibited by blockers of voltage-gated $\mathrm{Ca}^{2+}$ channels (Bixby et al., 1994; Williams et al., 1994). Any alteration in the mechanism by which membrane potential is regulated could possibly affect $\mathrm{Ca}^{2+}$ entry and downstream signaling in response to such a cue. For example, hyperpolarizing a growth cone or quickening the speed at which the membrane repolarizes after a depolarization would effectively decrease $\mathrm{Ca}^{2+}$ influx. $\mathrm{Kv}$ currents could also influence transduction of an extrinsic cue by modulating cAMP levels, because depolarization of cerebellar granule cells elevates cAMP (Cooper et al., 1998). Tight regulation of cAMP levels appears to be critical for axon guidance, given recent data showing that Xenopus spinal cord neurons sense a normally chemoattractive cue, such as BDNF, as inhibitory in the presence of a protein kinase A inhibitor (Song et al., 1997). Thus, small shifts in membrane potential, regulated by Kv channels, could provide an elegant gain control for incoming signals. Dampening membrane depolarizations would provide an effective mechanism to limit the period of signal transduction downstream of those cues that alter cAMP levels or cause $\mathrm{Ca}^{2+}$ entry. This model predicts that changes in membrane potential would sensitize or desensitize a growth cone to extrinsic cues. A comparable situation exists in the developing retina, where peptide growth factors promote survival of RGCs only when applied simultaneously with a depolarizing stimulus (Meyer-Franke et al., 1995).

Our data strongly support a novel role for $\mathrm{Kv}$ channels in the guidance of RGC axons. In the future, it will be important to determine how growth cone $\mathrm{Kv}$ channels influence the reaction to specific cues: either generally through regulation of $\left[\mathrm{Ca}^{2+}\right]_{i}$ or more selectively via modulation of the signal transduction of certain environmental cues.

\section{REFERENCES}

Arcangeli A, Becchetti A, Mannini A, Mugnai G, De Filippi P, Tarone G, Del Bene MR, Barletta E, Wanke E, Olivotto M (1993) Integrinmediated neurite outgrowth in neuroblastoma cells depends on the activation of potassium channels. J Cell Biol 122:1131-1143.

Barry DM, Xu H, Schuessler RB, Nerbonne JM (1998) Functional knockout of the transient outward current, long-QT syndrome, and cardiac remodeling in mice expressing a dominant-negative Kv4 alpha subunit. Circ Res 83:560-567.

Bixby JL, Grunwald GB, Bookman RJ (1994) Ca2+ influx and neurite growth in response to purified $\mathrm{N}$-Cadherin and laminin. J Cell Biol 127:1461-1475.

Brau ME, Dreyer F, Jonas P, Repp H, Vogel W (1990) A K+ channel in Xenopus nerve fibres selectively blocked by bee and snake toxins: binding and voltage-clamp experiments. J Physiol (Lond) 420:365-385.

Burg MG, Wu CF (1989) Central projections of peripheral mechanosensory cells with increased excitability in Drosophila mosaics. Dev Biol 131:505-514.

Burger C, Ribera AB (1996) Xenopus spinal neurons express Kv2 potassium channel transcripts during embryonic development. J Neurosci 16:1412-1421.

Catalano SM, Shatz CJ (1998) Activity-dependent cortical target selection by thalamic axons. Science 281:559-262.

Catsicas M, Bonness V, Becker D, Mobbs P (1998) Spontaneous $\mathrm{Ca}^{2+}$ transients and their transmission in the developing chick retina. Curr Biol 8:283-286.

Chien CB, Harris WA (1994) Axonal guidance from retina to tectum in embryonic Xenopus. Curr Top Dev Biol 29:135-169.

Chien CB, Rosenthal DE, Harris WA, Holt CE (1993) Navigational errors made by growth cones without filopodia in the embryonic $\mathrm{Xe}$ nopus brain. Neuron 11:237-251.

Cohen-Cory S, Fraser SE (1995) Effects of brain-derived neurotrophic factor on optic axon branching and remodelling in vivo. Nature 378:192-196.

Cooper DMF, Schell MJ, Thorn P, Irvine RF (1998) Regulation of adenylyl cyclase by membrane potential. J Biol Chem 273:27703-27707.

Cornel E, Holt C (1992) Precocious pathfinding: retinal axons can navigate in an axonless brain. Neuron 9:1001-1011.

Davenport RW, Kater SB (1992) Local increases in intracellular calcium elicit local filopodial responses in Helisoma neuronal growth cones. Neuron 9:405-416.

Ericson J, Muhr J, Jessell TM, Edlund T (1995) Sonic hedgehog: a common signal for ventral patterning along the rostrocaudal axis of the neural tube. Int J Dev Biol 39:809-816.

Gomez TM, Spitzer NC (1999) In vivo regulation of axon extension and pathfinding by growth-cone calcium transients. Nature 397:350-355.

Gottmann K, Lux HD (1995) Growth cone calcium ion channels: properties, clustering, and functional roles. Perspect Dev Neurobiol 2:371-377.

Gu X, Spitzer NC (1997) Breaking the code: regulation of neuronal differentiation by spontaneous calcium transients. Dev Neurosci 19:33-41.

Hamill OP, Marty A, Neher E, Sakmann B, Sigworth FJ (1981) Improved patch-clamp techniques for high resolution current recording from cells and cell-free membrane patches. Pflügers Arch 391:85-100.

Harris WA (1980) The effects of eliminating impulse activity on the development of the retinotectal projection in salamanders. J Comp Neurol 194:303-317.

Harris WA, Messersmith SL (1992) Two cellular inductions involved in photoreceptor determination in the Xenopus retina. Neuron 9:357-372.

Harris WA, Holt CE, Bonhoeffer F (1987) Retinal axons with and without their somata, growing to and arborizing in the tectum of Xenopus embryos: a time-lapse video study of single fibres in vivo. Development 101:123-133.

Harvey AL (1997) Recent studies on dendrotoxins and potassium ion channels. Gen Pharmacol 28:7-12.

Holtfreter J (1943) Properties and functions of the surface coat in amphibian embryos. J Exp Zool 93:251-323.

Itoh K, Ozaki M, Stevens B, Fields RD (1997) Activity-dependent regulation of $N$-cadherin in DRG neurons: differential regulation of $N$-cadherin, NCAM, and L1 by distinct patterns of action potentials. J Neurobiol 33:735-748.

Kater SB, Mills LR (1991) Regulation of growth cone behavior by calcium. J Neurosci 11:891-899.

Kater SB, Davenport RW, Guthrie PB (1994) Filopodia as detectors of 
environmental cues: signal integration through changes in growth cone calcium levels. Prog Brain Res 102:49-60.

Lautermilch NJ, Spitzer NC (1997) The KV4.3 Shal gene is developmentally upregulated in Xenopus embryos and encodes a potassium current modulated by arachidonic acid. Soc Neurosci Abstr. 23:1738.

Lnenicka GA, Arcaro KF, Calabro JM (1998) Activity-dependent development of calcium regulation in growing motor axons. J Neurosci 18:4966-4972.

McFarlane S, McNeill L, Holt CE (1995) FGF signaling and target recognition in the developing Xenopus visual system. Neuron 15:1017-1028.

Meyer-Franke A, Kaplan MR, Pfrieger FW, Barres BA (1995) Characterization of the signaling interactions that promote the survival and growth of developing retinal ganglion cells in culture. Neuron 15:805-819.

Meyer-Franke A, Wilkinson GA, Kruttgen A, Hu M, Munro E, Hanson MG Jr, Reichardt LF, Barres BA (1998) Depolarization and cAMP elevation rapidly recruit TrkB to the plasma membrane of CNS neurons. Neuron 21:681-693.

Metcalfe WK, Myers PZ, Trevarrow B, Bass MB, Kimmel CB (1990) Primary neurons that express the L2/HNK-1 carbohydrate during early development in the zebrafish. Development 110:491-504.

Mills LR, Kater SB (1990) Neuron-specific and state-specific differences in calcium homeostasis regulate the generation and degeneration of neuronal architecture. Neuron 4:149-163.

Neely MD, Nicholls JG (1995) Electrical activity, growth cone motility and the cytoskeleton. J Exp Biol 198:1433-1446.

Nieuwkoop PD, Faber J (1994) Normal table of Xenopus laevis (Daudin). New York, NY: Garland.

O'Dowd DK, Ribera AB, Spitzer NC (1988) Development of voltagedependent calcium, sodium, and potassium currents in Xenopus spinal neurons. J Neurosci 8:791-805.

Olson MD, Meyer RL (1994) Normal activity-dependent refinement in a compressed retinotectal projection in goldfish. J Comp Neurol 347:481-494.

Peckol EL, Zallen JA, Yarrow JC, Bargmann CI (1999) Sensory activity affects sensory axon development in C. elegans. Development 9:1891-1902.

Prada FA, Dorado ME, Quesada A, Prada C, Schwarz U, de la Rosa EJ (1995) Early expression of a novel radial glia antigen in the chick embryo. Glia 15:389-400.

Ribera AB (1990) A potassium channel gene is expressed at neural induction. Neuron 5:691-701.

Ribera AB, Nguyen DA (1993) Primary sensory neurons express a Shaker-like potassium channel gene. J Neurosci 13:4988-4996.

Ribera AB, Spitzer NC (1992) Developmental regulation of potassium channels and the impact on neuronal differentiation. Ion Channels $3: 1-38$.

Riehl R, Johnson K, Bradley R, Grunwald GB, Cornel E, Lilienbaum A, Holt CE (1996) Cadherin function is required for axon outgrowth in retinal ganglion cells in vivo. Neuron 17:837-848.

Robinson DW, Wang GY (1998) Development of intrinsic membrane properties in mammalian retinal ganglion cells. Semin Cell Dev Biol 9:301-310.

Rorig B, Grantyn R (1994) Ligand- and voltage-gated ion channels are expressed by embryonic mouse retinal neurones. NeuroReport 5:1197-1200.

Sakaguchi DS, Murphey RK, Hunt RK, Tompkins R (1984) The development of retinal ganglion cells in a tetraploid strain of Xenopus laevis: a morphological study utilizing intracellular dye injection. J Comp Neurol 224:231-251.

Schmidt JT, Buzzard M (1993) Activity-driven sharpening of the retinotectal projection in goldfish: development under stroboscopic illumination prevents sharpening. J Neurobiol 24:384-399.

Schmidt JT, Edwards DL, Stuermer C (1983) The re-establishment of synaptic transmission by regenerating optic axons in goldfish: time course and effects of blocking activity by intraocular injection of tetrodotoxin. Brain Res 269:15-27.

Shatz CJ (1990) Impulse activity and the patterning of connections during CNS development. Neuron 5:745-756.

Skaliora I, Scobey RP, Chalupa LM (1993) Prenatal development of excitability in cat retinal ganglion cells: action potentials and sodium currents. J Neurosci 13:313-323.

Skaliora I, Robinson DW, Scobey RP, Chalupa LM (1995) Properties of $\mathrm{K}^{+}$conductances in cat retinal ganglion cells during the period of activity-mediated refinements in retinofugal pathways. Eur J Neurosci 7:1558-1568.

Song HJ, Ming GL, Poo MM (1997) cAMP-induced switching in turning direction of nerve growth cones. Nature 388:275-279.

Sontheimer H, Kettenmann H, Schachner M, Trotter J (1991) The neural cell adhesion molecule $\left(N\right.$-CAM) modulates $\mathrm{K}^{+}$channels in cultured glial precursor cells. Eur J Neurosci 3:230-236.

Spitzer NC, Olson E, Gu X (1995) Spontaneous calcium transients regulate neuronal plasticity in developing neurons. J Neurobiol 26:316-324.

Sretavan DW, Shatz CJ, Stryker MP (1988) Modification of retinal ganglion cell axon morphology by prenatal infusion of tetrodotoxin. Nature 336:468-471.

Stuermer CA, Rohrer B, Munz H (1990) Development of the retinotectal projection in zebrafish embryos under TTX-induced neural-impulse blockade. J Neurosci 10:3615-3626.

Tongiorgi E, Righi M, Cattaneo A (1997) Activity-dependent dendritic targeting of BDNF and TrkB mRNAs in hippocampal neurons. J Neurosci 17:9492-9505.

Williams EJ, Walsh FS, Doherty P (1994) The production of arachidonic acid can account for calcium channel activation in the second messenger pathway underlying neurite outgrowth stimulated by NCAM, $N$-cadherin, and L1. J Neurochem 62:1231-1234.

Wong RO (1995) Effects of glutamate and its analogs on intracellular calcium levels in the developing retina. Vis Neurosci 12:907-917.

Worley T, Holt C (1996) Inhibition of protein tyrosine kinases impairs axon extension in the embryonic optic tract. J Neurosci 16:2294-2306.

Yamashita M, Fukuda Y (1993) Calcium channels and GABA receptors in the early embryonic chick retina. J Neurobiol 24:1600-1614. 